

Zurich Open Repository and Archive

University of Zurich

University Library

Strickhofstrasse 39

CH-8057 Zurich

www.zora.uzh.ch

Year: 2015

\title{
Quantitative imaging
}

Alkadhi, Hatem ; Frauenfelder, Thomas ; Andreisek, Gustav ; Boss, Andreas

DOI: https://doi.org/10.1097/RLI.0000000000000139

Posted at the Zurich Open Repository and Archive, University of Zurich

ZORA URL: https://doi.org/10.5167/uzh-109830

Journal Article

Published Version

Originally published at:

Alkadhi, Hatem; Frauenfelder, Thomas; Andreisek, Gustav; Boss, Andreas (2015). Quantitative imaging. Investigative Radiology, 50(4):187.

DOI: https://doi.org/10.1097/RLI.0000000000000139 


\title{
Quantitative Imaging
}

\author{
Hatem Alkadhi, MD, MPH, EBCR, Thomas Frauenfelder, MD, MAS, \\ Gustav Andreisek, MD, MBA, and Andreas Boss, MD, PhD
}

$\mathrm{Q}$ uantitative imaging characterizes techniques in which measurable parameters are extracted from voxels for describing physical, chemical, or biological properties of tissue. Radiology today is increasingly confronted with the demand of obtaining functional imaging information beyond morphology. This quantitative information should result in an improved characterization and stratification of disease and should help in the prediction or assessment of response to treatment, with the ultimate goal of optimizing clinical decision making and patient outcome.

The most prevalent current topic for quantitative imaging is oncology, ${ }^{1-7}$ where new targeted anticancer therapies result in response patterns that often cannot be determined by conventional morphologic imaging alone. In this scenario, functional imaging adds to the understanding of the prediction and assessment of therapy response. However, oncology is not the sole field for the application of quantitative imaging. Quantitative imaging today proves its usefulness and added value also in musculoskeletal ${ }^{8,9}$ and lung ${ }^{10}$ imaging.

This special issue of Investigative Radiology is dedicated to the most recent research in the field of quantitative imaging focusing on magnetic resonance imaging, ${ }^{2,3,5-8,11-13}$ computed tomography, ${ }^{1,9,10,14}$ and ultrasound, ${ }^{4}$ including a broad range of applications. More recently introduced techniques for data evaluation such as texture analysis ${ }^{7,10}$ are covered, and in a similar manner, although pre-clinical in nature, photon counting computed tomography technology. ${ }^{15}$

This intriguing topic of the special issue was reflected by a very large number of submissions, necessitating a highly competitive review process. We thank all authors for their submissions and especially all reviewers for their outstanding reviews. As a result, the readers will find a total of 15 highquality articles on quantitative imaging with various modalities, measures, and applications.

\section{REFERENCES}

1. Wu D, Tan M, Zhou M, et al. Liver computed tomographic perfusion in the assessment of microvascular invasion in patients with small hepatocellular carcinoma. Invest Radiol. 2015;50:188-194.

2. Li X, Abramson RG, Arlinghaus LR, et al. Multiparametric magnetic resonance imaging for predicting pathological response after the first cycle of neoadjuvant chemotherapy in breast cancer. Invest Radiol. 2015;50:195-204.

3. Iima M, Yano K, Kataoka M, et al. Quantitative non-gaussian diffusion and intravoxel incoherent motion magnetic resonance imaging: differentiation of malignant and benign breast lesions. Invest Radiol. 2015;50:205-211.

4. Pitre-Champagnat S, Leguerney I, Bosq J, et al. Dynamic contrast-enhanced ultrasound parametric maps to evaluate intratumoral vascularization. Invest Radiol. 2015;50:212-217.

5. Panagiotaki E, Chan RW, Dikaios N, et al. Microstructural characterization of normal and malignant human prostate tissue with vascular, extracellular, and restricted diffusion for cytometry in tumours magnetic resonance imaging. Invest Radiol. 2015;50:218-227.

6. Priola AM, Priola SM, Giraudo MT, et al. Chemical-shift and diffusion-weighted magnetic resonance imaging of thymus in myasthenia gravis: usefulness of quantitative assessment. Invest Radiol. 2015;50:228-238.

7. De Cecco CN, Ganeshan B, Ciolina M, et al. Texture analysis as imaging biomarker of tumoral response to neoadjuvant chemoradiotherapy in rectal cancer patients studied with 3-T magnetic resonance. Invest Radiol. 2015;50:239-245.

8. Zbýň Š, Brix MO, Juras V, et al. Sodium magnetic resonance imaging of ankle joint in cadaver specimens, volunteers, and patients after different cartilage repair techniques at $7 \mathrm{t}$ : initial results. Invest Radiol. 2015;50:246-254.

9. Diekhoff T, Kiefer T, Stroux A, et al. Detection and characterization of crystal suspensions using single-source dual-energy computed tomography: a phantom model of crystal arthropathies. Invest Radiol. 2015;50:255-260.

10. Depeursinge A, Chin AS, Leung AN, et al. Automated classification of usual interstitial pneumonia using regional volumetric texture analysis in high-resolution computed tomography. Invest Radiol. 2015;50:261-267.

11. Dannhauer T, Ruhdorfer A, Wirth W, et al. Quantitative relationship of thigh adipose tissue with pain, radiographic status, and progression of knee osteoarthritis: longitudinal findings from the osteoarthritis initiative. Invest Radiol. 2015;50:268-274.

12. Handayani A, Triadyaksa P, Dijkstra $\mathrm{H}$, et al. Intermodel agreement of myocardial blood flow estimation from stress-rest myocardial perfusion magnetic resonance imaging in patients with coronary artery disease. Invest Radiol. 2015;50:275-282.

13. Corona-Villalobos CP, Halappa VG, Bonekamp S, et al. Functional magnetic resonance imaging response of targeted tumor burden and its impact on survival in patients with hepatocellular carcinoma. Invest Radiol. 2015;50:283-289.

14. Yoon JH, Lee JM, Klotz E, et al. Estimation of hepatic extracellular volume fraction using multiphasic liver computed tomography for hepatic fibrosis grading. Invest Radiol. 2015;50:290-296.

15. de Vries A, Roessl E, Kneepkens E, et al. Quantitative spectral k-edge imaging in preclinical photon-counting x-ray computed tomography. Invest Radiol. 2015;50:297-304.

Received for publication December 16, 2014; and accepted for publication, after revision, December 18, 2014.

From the Institute of Diagnostic and Interventional Radiology, University Hospital Zurich, Zurich, Switzerland.

Conflicts of interest and sources of funding: none declared.

Reprints: Hatem Alkadhi, MD, MPH, EBCR, Institute of Diagnostic and Interventional Radiology, University Hospital Zurich, Raemistr. 100, Zurich, Switzerland 8190. E-mail: hatem.alkadhi@usz.ch.

Copyright (C) 2015 Wolters Kluwer Health, Inc. All rights reserved.

ISSN: 0020-9996/15/5004-0187 